\title{
Dynamic changes of gangliosides expression during the differentiation of embryonic and mesenchymal stem cells into neural cells
}

\author{
Dong-Hoon Kwak ${ }^{1 *}$, Kweon $\mathrm{Yu}^{2 *}$, \\ Sung-Min Kim ${ }^{1}$, Dea-Hoon Lee ${ }^{1}$, \\ Sun-Mi Kim ${ }^{1}$, Ji-Ung Jung ${ }^{1}$, \\ Jung-Woo Seo ${ }^{1}$, Nari Kim ${ }^{1,3}$, Seoul Lee ${ }^{3}$, \\ Kyu-Yong Jung ${ }^{3}$, Hyung-Keun You ${ }^{4}$, \\ Hyun-A Kim ${ }^{4}$ and Young-Kug Choo ${ }^{1,5}$ \\ ${ }^{1}$ Department of Biological Science \\ College of Natural Sciences \\ Wonkwang University \\ Iksan 570-749, Korea \\ ${ }^{2}$ Center for Development and Differentiation \\ Korea Research Institute of \\ Bioscience and Biotechnology (KRIBB) \\ Daejeon 305-333, Korea \\ ${ }^{3}$ Department of Pharmacology \\ ${ }^{4}$ Department of Periodontology \\ Wonkwang University School of Dentistry \\ Iksan 570-749, Korea \\ ${ }^{5}$ Corresponding author: Tel, 82-63-850-6087; \\ Fax, 82-63-857-8837; E-mail, ykchoo@wonkwang.ac.kr \\ ${ }^{*}$ These authors contributed equally to this work.
}

Accepted 25 October 2006

Abbreviations: AP, alkaline phosphatase; EB, embryonic body; GSLs, glycosphingolipids, HPTLC, high performance thin layer chromatography; mESC, mouse embryonic stem cell; MSC, mesechymal stem cell; RT-PCR, reverse transcriptase-PCR; SSEA-1, stagespecific embryonic antigen

\begin{abstract}
Stem cells are used for the investigation of developmental processes at both cellular and organism levels and offer tremendous potentials for clinical applications as an unlimited source for transplantation. Gangliosides, sialic acid-conjugated glycosphingolipids, play important regulatory roles in cell proliferation and differentiation. How ever, their expression patterns in stem cells and during neuronal differentiation are not known. Here, we investigated expression of gangliosides during the growth of mouse embryonic stem cells (mESCs), mesenchymal stem cells (MSCs) and differentiated
\end{abstract}

neuronal cells by using high-performance thin-layer chromatography (HPTLC). Monosialoganglioside 1 (GM1) was expressed in mESCs and MSCs, while GM3 and GD3 were expressed in embryonic bodies. In the 9-day old differentiated neuronal cells from mESCs cells and MSCs, GM1 and GT1b were expressed. Results from immunostaining were consis tent with those observed by HPTLC assay. These suggest that gangliosides are specifically expressed according to differentiation of mESCs and MSCs into neuronal cells and expressional difference of gangliosides may be a useful marker to identify differentiation of mESCs and MSCs into neuronal cells.

Keywords: cell differentiation; embryonic development; fluorescent antibody techniques; gangliosides; mesenchymal stem cells; stem cells

\section{Introduction}

Gangliosides are complex glycosphingolipids (GSLs) with $\mathrm{N}$-acetylneuraminic acids (NeuAc), which are major cytoplasmic membrane constituents in mammalian cells, and play important regulatory roles in cell proliferation and differentiation (Svennerholm, 1980; Nojiri et al., 1986; Hakomori, 1990). Cellular gangliosides act as physiological modulators for growth factor mediated cell proliferation ( $\mathrm{Li}$ et al., 2000). Gangliosides are highly expressed in the vertebrate central nervous system (Ledeen and $\mathrm{Yu}$, 1982), and the antibodies against gangliosides synthases detect the distribution of gangliosides in tissue and cells (Choo et al., 2001). For example, monosialoganglioside 3 (GM3) is expressed in the mouse ovary tissue and rat glomerular mesangial cells (Kwak et al., 2003). Survival of differentiated stem cells depends on the inhibition of the ganglioside biosynthesis (Liour and Yu, 2002). These suggest that gangliosides may regulate the growth and differentiation of stem cells.

Stem cells can be used for the study of developmental processes and offer tremendous potentials for clinical applications as an unlimited source for transplantation and tissue regeneration therapies (Fortier, 2005). Mouse embryonic stem cells (mESCs) are pluripotent cells which are generated from the inner cell mass of blastocysts (Evans and Kaufman, 
1981). When mESCs are cultured with mouse embryonic fibroblast, feeder cells, they proliferate indefinitely and retain the potential to differentiate into various lineages of all three primary germ layers (Martin, 1981). Various studies conducted to differentiate mESCs into neuronal cells, cardiomyocytes, muscle cells, and insulin secreting cells (He et al., 2005; Milne et al., 2005; Wei et al., 2005). Mesenchymal stem cells (MSCs) isolated from adult bone marrow are multipotent cells and can be differentiate into cartilage, tendon, fat, or bone marrow stroma (Woodbury et al., 2000). Recent studies demonstrated the possibility that MSCs can be differentiated into other cell types such as cardiac myoblasts, endothelial cells, or neurons (Zhao et al., 2002; Piao et al., 2005). However, expression of gangliosides during the differentiation of mESCs and MSCs into neuronal cells is not known.

In this study, we investigated the spatiotemporal expression of gangliosides during differentiation of mESCs and MSCs into neuronal cells and whether ganglioside expression can be used as a biomarker for identification of neuronal differentiation of mESCs and MSCs in culture.

\section{Materials and Methods}

\section{Mouse ES cells and mesenchymal stem cell culture}

J1 mESCs were maintained in the undifferentiated state with feeder cells and leukemia inhibitor factor and cultured in the mouse ES culture medium at $37^{\circ} \mathrm{C}$ as described previously (Kawai et al., 1998). MSCs originated from human periodontal bone marrow were primarily cultured as described previously (Woodbury et al., 2000). At passage 6, MSCs were transferred to DMEM media contained $20 \%$ FBS, and passages 6-20 were used for experiment.

\section{Embryonic body formation and neuronal differentiation}

Embryonic bodies (EBs) were formed as described previously (Zhang et al., 2005). To differentiate EBs into neuronal cells, retinoic acid $(5 \mu \mathrm{M})$ was treated for 4 days (Okada et al., 2004). Neuronal differentiation of MSCs was performed as described previously (Kotobuki et al., 2004).

\section{Stem cell marker staining}

Stage-specific embryonic antigen (SSEA-1), mESCs marker, was detected by the antibody against SSEA-1 (Chemicon) and FITC-conjugated IgG (Sigma). To detect alkaline phosphatase (AP), mESC colonies were fixed in $4 \%$ formaldehyde for $15 \mathrm{~min}$ and stained with Fast red TR/naphthol AS-MX for 15 min (Sigma). CD44 antibody (ImTec Diagnostics, Belgium) was used for a MSCs marker.

\section{RT-PCR}

Total RNA from mESCs was isolated with the Trizol Kit (Sangon, China). RT-PCR was carried out using the one-step RT-PCR kit (Promega) with the Eppendorf Mastercycler. PCR conditions were $94^{\circ} \mathrm{C}$ for 2 min, followed by 30 cycles of $94^{\circ} \mathrm{C}$ for $30 \mathrm{~s}, 60^{\circ} \mathrm{C}$ for $1 \mathrm{~min}$, and $68^{\circ} \mathrm{C}$ for $2 \mathrm{~min}$, and final extension at $68^{\circ} \mathrm{C}$ for $7 \mathrm{~min}$ (Kim et al., 2005). Forward (5'GGCGTTCTCTTTGGAAAGGTGTTC3') and reverse (5'CTCGAACCACATCCTTCTCT3') primers were used for the Oct4 gene (Bortvin et al., 2003), and forward (5'GGCAGCTACAGCATGATGCAGGAGC3') and reverse (5'CTGGTCATGGAGTTGTACTGCAGG3') primers were used for the Sox2 gene (Zappone et al., 2000).

\section{Ganglioside purification and high-performance thin-layer chromatography}

Gangliosides of mESCs, EBs, MSCs, and differentiated neuronal cells were extracted and fractionated according to the procedure described previously (Svennerholm et al., 1957). Gangliosides were analyzed by high-performance thin-layer chromatography (HPTLC) plates (Merck, Darmstadt, FRG). The solvent system for developing chromatograms was chloroform/methanol/0.22\% $\mathrm{CaCl}_{2}$ in water (55: $45:$ $10, v / v / v)$. Resorcinol staining was used for detection of gangliosides.

\section{Immunofluorescence of gangliosides}

mESCs, EBs, MSCs, and differentiated neuronal cells were fixed on a gelatin-coated slide chamber. The cells were fixed with $4 \%$ formaldehyde at $4{ }^{\circ} \mathrm{C}$ for $2 \mathrm{~h}$ (Graus et al., 1984) and washed twice with PBS at room temperature for $10 \mathrm{~min}$, followed by incubation with $5 \%$ BSA in PBS for $15 \mathrm{~min}$ at room temperature. After washing with PBS twice, they were incubated with monoclonal antibodies (MAbs) diluted in PBS (1:100) containing 5\% BSA at $4{ }^{\circ} \mathrm{C}$ for overnight. Cells were washed 4 times with cold PBS, and then incubated with FITC-conjugated goat antimouse $\lg \mathrm{M}$ and $\lg \mathrm{G}$ antibodies (Sigma) diluted in PBS (1:100) for $1 \mathrm{~h}$ (Choi et al., 2004), followed by washing and sealing with a cover slip. The fluorescence intensity was measured by confocal laser scanning microscopy (Olympus Co.). MAbs specific for ganglioside GM3, GM2, GM1, GD1a, GD1b, GD3, GQ1b and GT1b were used (Seikagaku Co., Japan). A control was incubated without primary antibodies. 
A

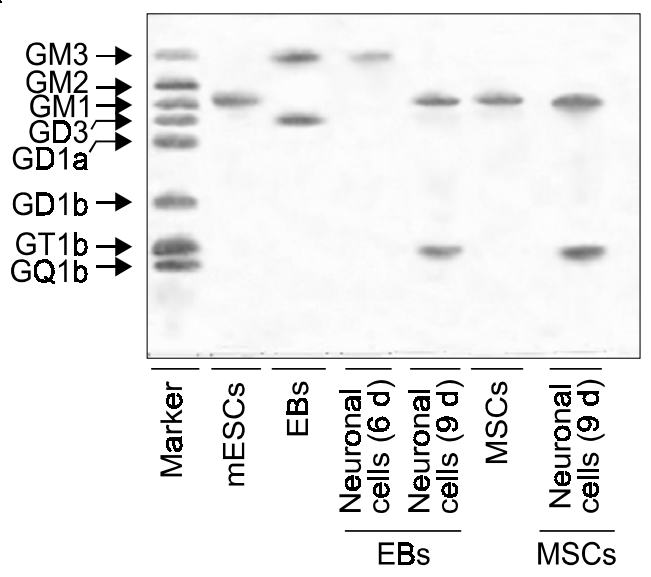

B

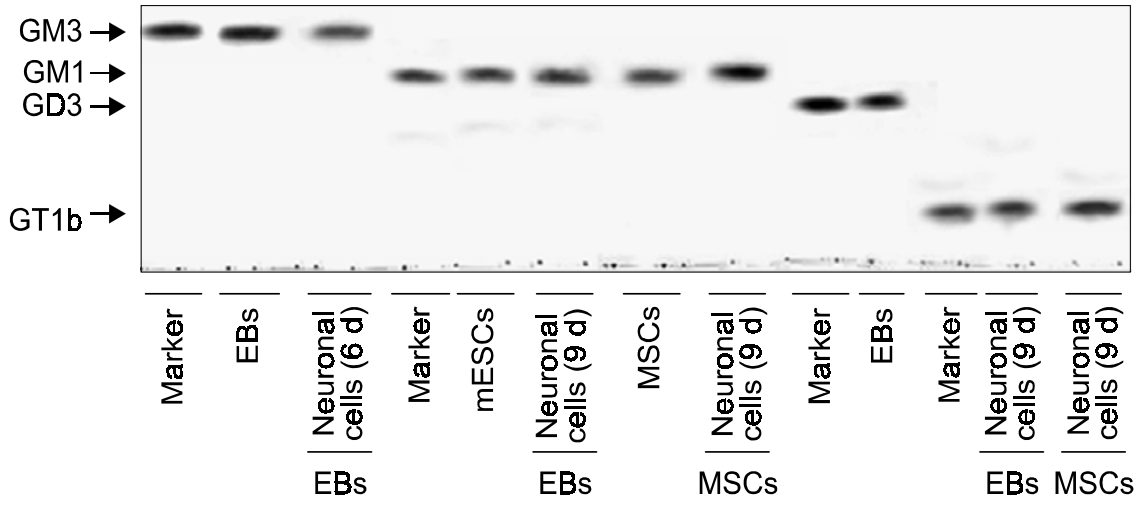

Figure 1. Differential expression of gangliosides in mESCs, EBs, MSCs and differentiated neuronal cells. Ganglioside expression ( $1 \mu \mathrm{g} / \mathrm{lane}$ ) was analyzed using HPTLC and resorcinol method $(A)$, and gangliosides on HPTLC plates were reacted with monoclonal antibodies against ganglioside GM3, GM1, GD3 and GT1b (B).

For delipidated controls, the cells were treated, prior to the staining, first with methanol and then with chloroform/methanol $(1: 1, v / v)$ for 10 min each.

\section{Immunofluorescence for differentiated neuronal cells}

EBs and differentiated neuronal cells were fixed by $4 \%$ paraformaldehyde solution for $2 \mathrm{~h}$ and washed with PBS containing $0.1 \%$ Triton X-100, followed by blocking with PBS solution containing 5\% BSA. Cells were incubated for $1 \mathrm{~h}$ with a monoclonal anti-mouse MAP2 antibody. The secondary antibody was goat anti-mouse $\lg _{1}$ conjugated with TRICT. The fluorescence intensity was measured by fluorescence microscopy (Olympus Co.). A control was incubated without primary antibodies. For delipidated controls, the cells were treated, prior to the staining, first with methanol and then with chloroform/methanol (1:1, $\mathrm{v} / \mathrm{v}$ ) for $10 \mathrm{~min}$ each.

\section{Results}

\section{Ganglioside expression}

Gangliosides extracted from mESCs, EBs, MSCs and differentiated neuronal cells were analyzed by HPTLC, and the representative results with 5 times are shown in Figure 1A. Ganglioside GM1 was detected in the mESCs, while gangliosides GM3 and GD3 were detected in the EBs. Ganglioside GM3 was observed in the neuronal cells differentiated from mESCs at 6 days after induction of differentiation, whereas ganglioside GM1 and GT1b were expressed in the neuronal cells differentiated from mESCs at 9 days after induction of differentiation. MSCs expressed ganglioside GM1, and ganglioside GM1 and GT1b were observed in the neuronal cells differentiated from MSCs at 9 days after induction of differentiation. As shown in Figure 1B, these results were also confirmed by the HPTLC immunostaining. 
A

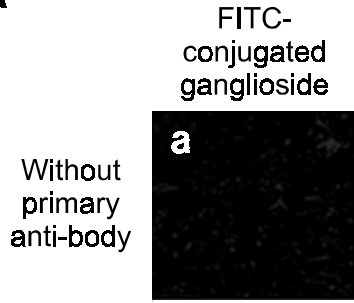

GM1
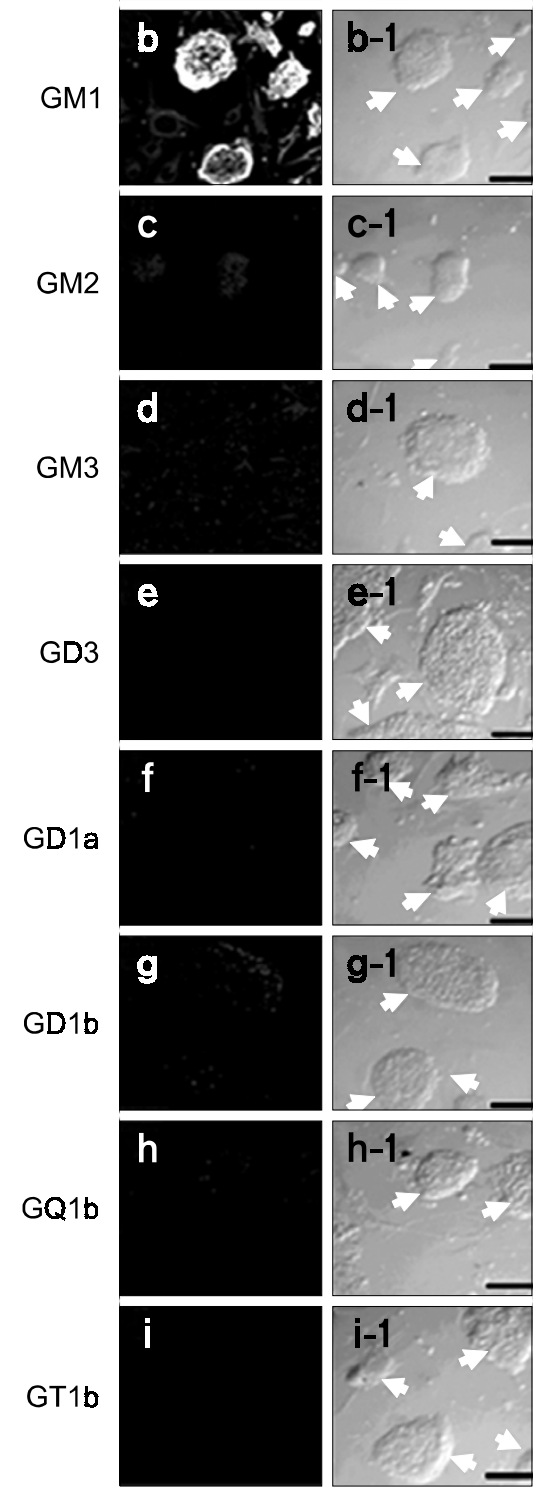

B
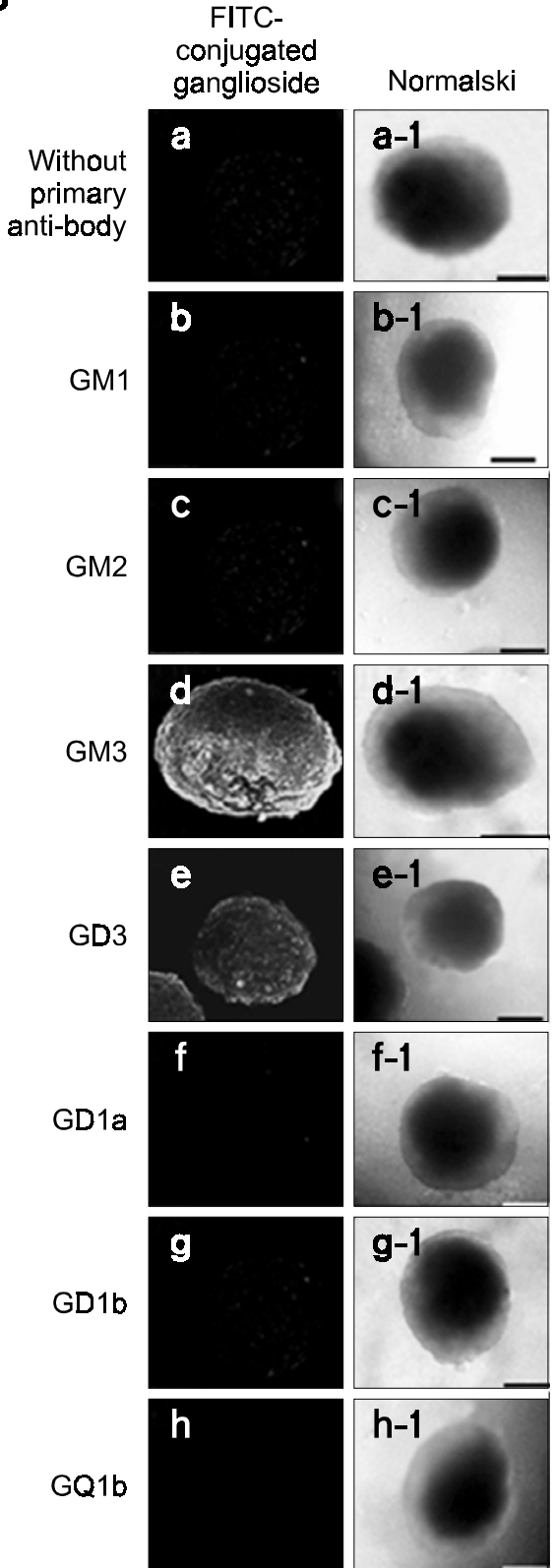

GT1b
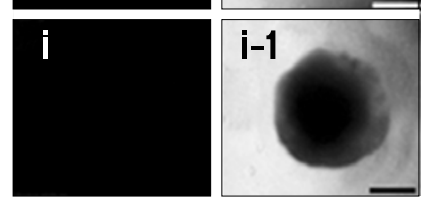

Figure 2. Immunostaining of gangliosides in mESCs and EBs. mESCs (A) and EBs (B) were immunostained with monoclonal antibodies specific for gangliosides, and immunoreactivity was observed by laser scanning confocal microscopy. Arrow indicates mES colony. Scale bars are $150 \mu \mathrm{m}$.

Immunofluorescence of gangliosides in mESCs and EBs

To confirm the results shown in Figure 1, we investigated the localization of gangliosides in mESCs and EBs. As shown in Figure 2A, mESCs strongly expressed ganglioside GM1, but other ganglioside GM2, GM3, GD1a, GD1b, GD3 and GQ1b were not detected. In contrast to these, immunostaining 
A

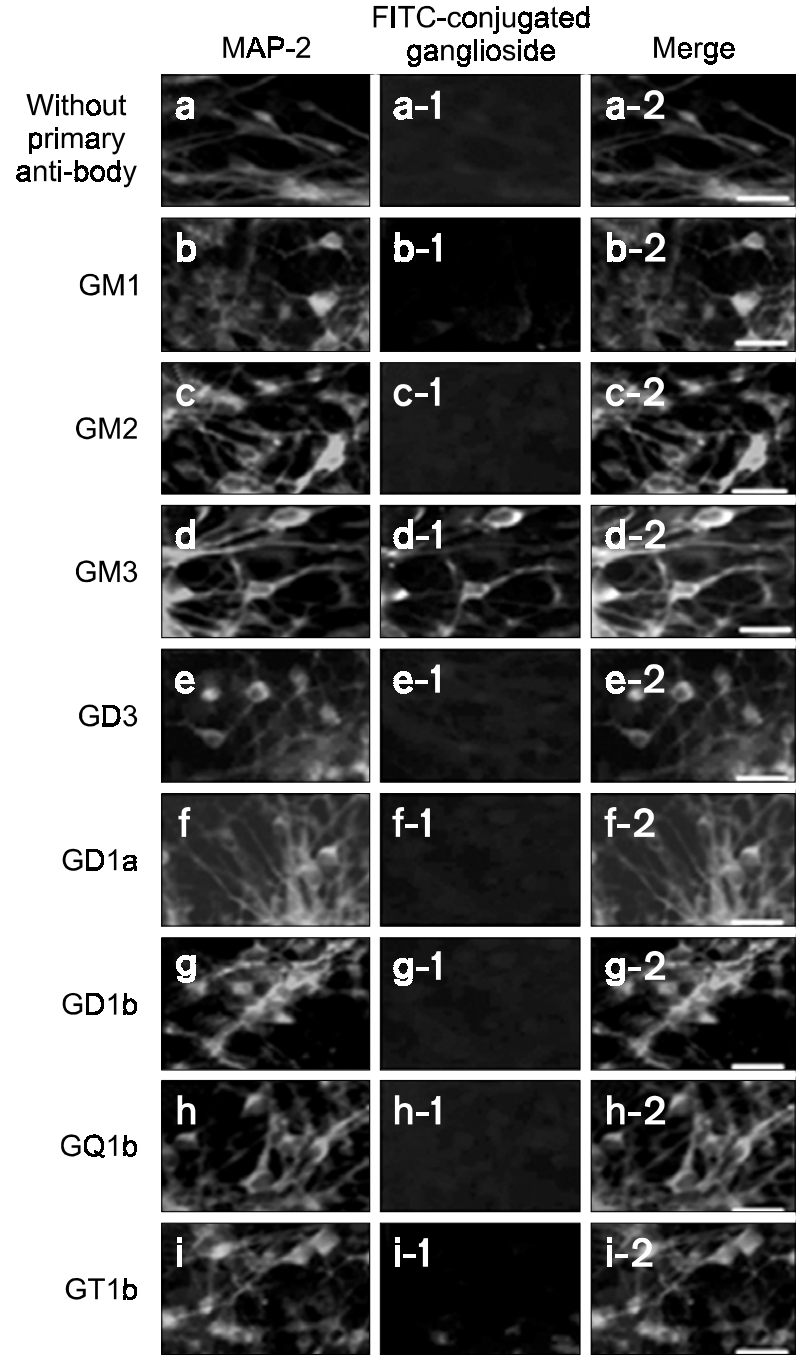

$\mathbf{B}$

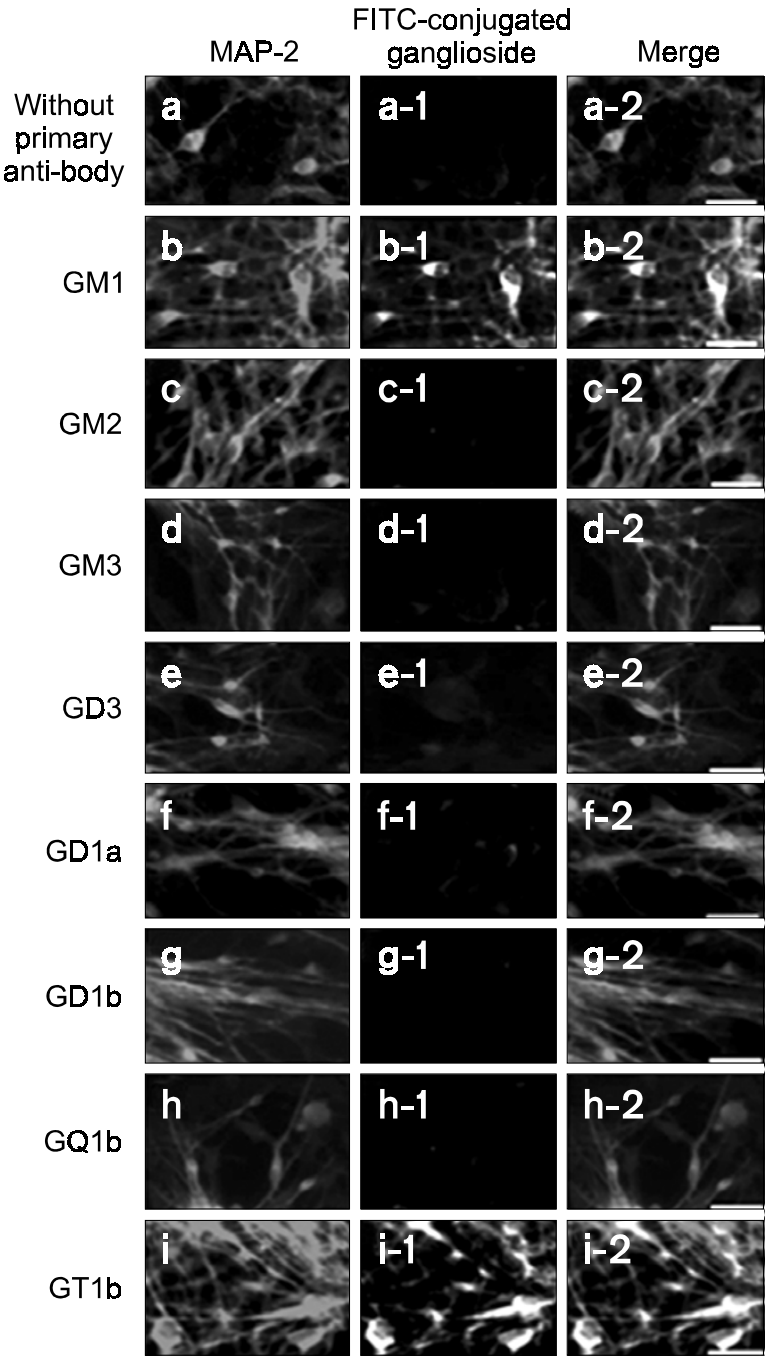

Figure 3. Expression of MAP-2 and gangliosides in the neuronal cells differentiated from EBs. At 6 (A) and 9 (B) days after induction of differentiation, neuron-like cells were double-stained with the neuronal marker MAP-2- and ganglioside-specific antibodies. Scale bars are $10 \mu \mathrm{m}$.

revealed that EBs strongly expressed ganglioside GM3 and GD3, but ganglioside GD1a, GD1b, GM1, and GT1b were not expressed in EB (Figure 2B). These results are consistent with those obtained by HTPLC.

\section{Ganglioside expression in the neuronal cells differentiated from EBs}

Neuron-like cells appeared at 6 days after induction of differentiation, and these cells strongly expressed MAP-2, a neuronal cell marker (Figure 3A, a-i). Compared with gangliosides expression in EBs, ganglioside GM3 expression was significantly decreased in the neuronal cells at 6 days after differentiation
(Figure $3 A, d-1$ ), and other gangliosides in these cells were not detected (Figure $3 \mathrm{~A}, \mathrm{~b}-1-\mathrm{c}-1$ and e-1-i-1). The merged image between MAP-2 and ganglioside GM3 (Figure 3A, d-2) showed that GM3 was localized in the membranes of neuronal cell bodies. At 9 days after induction of differentiation, neuronal cells still expressed MAP-2 (Figure 3B, a-i) and ganglioside GM1 (Figure $3 \mathrm{~B}, \mathrm{~b}-1$ ) and GT1b (Figure 3B, i-1). However, these cells did not express other ganglioside GM2, GM3, GD1a, GD1b, GD3 and GQ1b (Figure 3B, c-1-h-1). The merged images showed that ganglioside GM1 and GT1b were localized mainly in the neuronal cell bodies (Figure $3 \mathrm{~B}, \mathrm{~b}-2$ and $\mathrm{i}-2)$. 
A

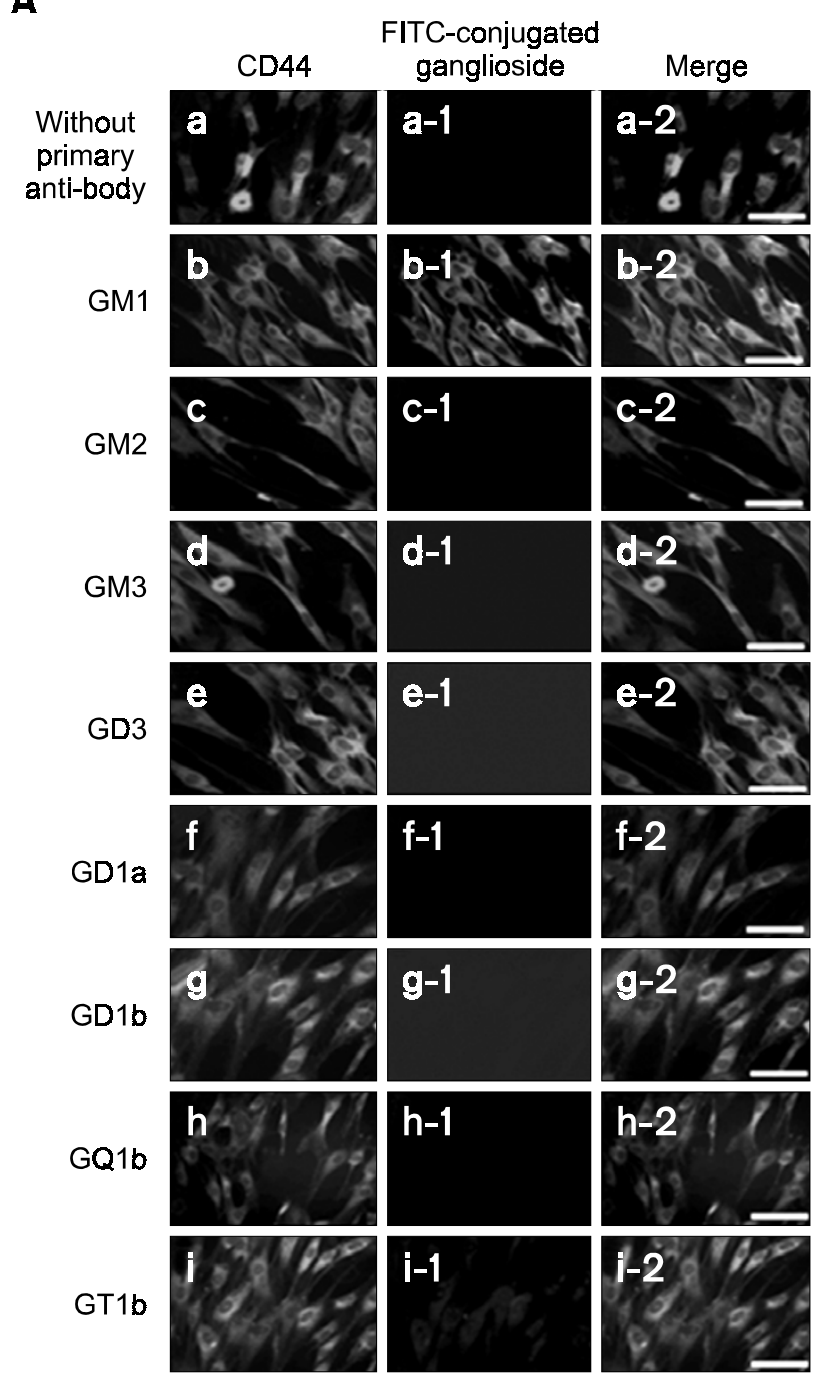

B

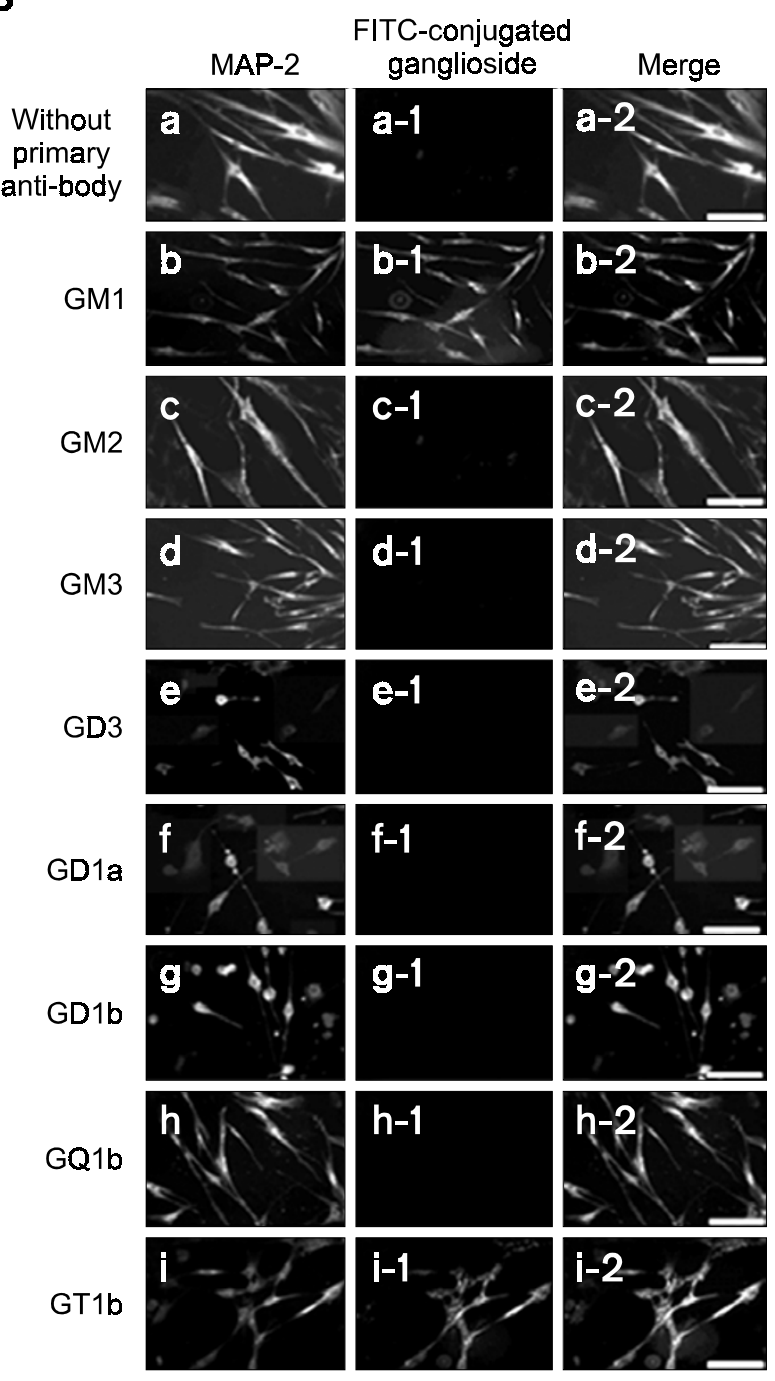

Figure 4. Expression of MAP-2 and gangliosides in the neuronal cells differentiated from MSCs. MSCs (A) and neuronal cells differentiated from MSCs at 9 days after induction of differentiation (B) were double-stained with the neuronal marker MAP-2- and ganglioside-specific antibodies. Scale bars are $10 \mu \mathrm{m}$.

\section{Ganglioside expression in the neuronal cells differentiated from MSCs}

MSCs expressed CD44 (Figure 4A, a-i), a mesenchymal cell marker, and ganglioside GM1 (Figure $4 A, b-1)$. Merged images showed that CD44 and ganglioside GM1 were mainly expressed in the cytoplasm of MSCs (Figure 4A and b-2). However, these cells did not express other gangliosides examined in this study (Figure $4 \mathrm{~A}$ and $\mathrm{c}-1-\mathrm{i}-1$ ). Neuronal cells differentiated from MSCs at 9 days after induction of differentiation strongly expressed MAP-2 (Figure 4B, a-i) and ganglioside GM1 (Figure $4 \mathrm{~B}$ and $\mathrm{b}-1$ ) and $\mathrm{GT} 1 \mathrm{~b}$ (Figure $4 \mathrm{~B}$ and $\mathrm{i}-1$ ), but other gangliosides (Figure 4B and $c-1-h-1$ ) were not expressed in these cells. Merged images showed that ganglioside GM1 and GT1b were mainly expressed in the neuronal cell bodies and axons (Figure 4B, b-2 and $i-2)$.

\section{Discussion}

Glycosphingolipids are involved in several cellular processes including cell adhesion, cell-cell interaction, embryogenesis and development and differentiation of cells (Bektas and Spiegel, 2004). Because the previous studies suggested that gangliosides are important for neuronal differentiation (Ledeen and $\mathrm{Yu}$, 1982), this study investigated differential expression of gangliosides during neuronal differentiation from mESCs and MSCs. Ganglioside GM1 was expres- 
sed in mESCs and MSCs, and EBs mainly expressed ganglioside GM3 and GD3. In contrast to these, neuronal cells differentiated from EBs at 6 days after induction of differentiation expressed only ganglioside GM3, and the neuronal cells differentiated from EBs and MSCs at 9 days after initiating differentiation expressed both ganglioside GM1 and GT1b. These differential expressions suggest that gangliosides may regulate the differentiation of $\mathrm{mESCs}$ and MSCs into neuronal cells and that ganglioside expression can be used as a marker for identification of neuronal differentiation from EBs and MSCs.

We firstly examined the cellular biological characteristics of undifferentiated mESCs to be used in this study and observed that mESCs obviously expressed the SSEA-1, a cell surface marker for mESCs and showed a round and compact morphology (data not shown). Oct4 and Sox2, a specific undifferentiated ES cell marker genes (Zappone et al., 2000; Bortvin et al., 2003), in undifferentiated mESCs were detected after RT-PCR with their appropriate sizes, and cells were also stained positively for alkaline phosphate. These results indicate that $\mathrm{mESC}$ s used in this study maintains undifferentiated properties of ES cells.

Using HPTLC and immunofluorescence method, this study observed only ganglioside GM1 expression in mESCs and MSCs, and it can be considered that these expressional patterns are relatively simple compared to those observed in the other types of cells such as ovarian and mesangial cells (Choo et al., 2001; Kwak et al., 2003), and we carefully consider that simple pattern of ganglioside expression in mESCs and MSCs may be related with a specific property of cell differentiation. Gangliosides in membranes regulate cell growth through the modulation of protein kinases and growth factor-mediated cell proliferation (Gouni-Berthold et al., 2001). It has been also suggested that ganglioside GM1 is considered to protect cells from apoptosis in neuronal PC 12 cells and heart fibroblasts (Ferrari et al., 1995; Cavallini et al., 1999). In the physiologically relevant study, ganglioside GM1 protects the mouse heart from hypoxic cell death. These may lead us to consider that ganglioside GM1 expressed in mESCs and MSCs may have a protective role against apoptosis, resulted in growth and proliferation of mESCs and MSCs.

Generating differentiated cell types from embryonic stem cells is preformed through the formation of EBs, in which embryonic stem cells spontaneously developed into the multicellular aggregates containing differentiated and undifferentiated embryonic stem cells. They are similar to the embryos of the egg-cylinder stage. EBs recapitulate many aspects of the lineagespecific differentiation and temporal and spatial gene expression patterns of early embryogenesis (Leahy et al., 1999). In the early stage of embryogenesis, ganglioside GD3 is found in many embryonic tissues. The presence of ganglioside GD3 is generally considered as the high proliferate state of cells (Berra et al., 1985). Ganglioside GM3 is also found in the early stage of embryonic development and plays important roles in cell-cell adhesion, differentiation, and proliferation (Kwak et al., 2003). These suggest that ganglioside GM3 and GD3 expressed in the EBs may regulate the cell differentiation and/or proliferation.

Previous studies suggested that gangliosides are important for neuronal differentiation (Hakomori et al., 1990). For example, ganglioside GM1 is widely distributed throughout the peripheral nervous system and has regulatory roles during neurogenesis and regeneration of injured peripheral nerves (OgawaGoto et al., 1992; Stojiljkovic et al., 1996). Ganglioside GT1b is expressed in the synapses of the brain (Kotani et al., 1993). Exposure of the neurons to ganglioside GT1b for 3 days drastically enhances actin-rich dendrite generation (Higashi and Chen, 2004). These reports indicate an important role of ganglioside GM3, GM1 and GT1b in neurogenesis and may support the results obtained in this study. We observed expression of ganglioside GM1 and GT1b in the 9-day old differentiated neuronal cells from EBs and MSCs. These results may suggest that ganglioside GM1 and GT1b may be necessary for differentiation of mESCs and MSCs into neuronal cells. In summary, we provide evidences that ganglioside GM1 and GT1b specifically express during the differentiations of mESCs and MSCs into neuronal cells, and these may offer new information which differential expression of gangliosides can be used as a useful biomarker to identify neuronal differentiation of mESCs and MSCs.

\section{Acknowledgment}

We thank Dr. M. Hoshi (Graduate School of Science and Technology, Keio University, Yokohama, Japan) for numerous suggestions and comments on the subjects. This study was supported by a grant (R012004-0000-10811-0 and M0619000005-06N190000510) from the Korea Science and Engineering Foundation.

\section{References}

Bektas M, Spiegel S. Glycosphingolipids and cell death. Glycoconj J 2004;20:39-47

Berra B, Gaini SM, Riboni L. Correlation between ganglioside distribution and histological grading of human astrocytomas. 
Int J Cancer 1985;36:363-6

Bortvin A, Eggan K, Skaletsky H, Akutsu H, Berry DL, Yanagimachi RD, Page C, Jaenisch R. Incomplete reactivation of Oct4-related genes in mouse embryos cloned from somatic nuclei. Development 2003;130:1673-80

Cavallini L, Venerando R, Miotto G, Alexandre A. Ganglioside GM1 protection from apoptosis of rat heart fibroblasts. Arch Biochem Biophys 1999; 5:156-62

Choi SC, Yoon JH, Shim WJ, Ro YM, Lim DS. 5-azacytidine induces cardiac differentiation of P19 embryonic stem cells. Exp Mol Med 2004;36:515-23

Choo YK, Ichikawa S, Hirabayashi Y. Developmental patterns of ceramide glucosyltransferase (GlcT-1) expression in the mouse: in situ hybridization using DIG-labeled RNA probes. Mol Cells 2001;11:346-51

Evans MJ, Kaufman MH. Establishment in culture of pluripotent cells from mouse embryos. Nature 1981;292:154-6

Ferrari G, Yan CY, Greene LA. N-acetylcysteine (D- and L-stereoisomers) prevents apoptotic death of neuronal cells. J Neurosci 1995;15:2857-66

Fortier LA. Stem cell: classifications, controversies, and clinical applications. Veter Surg 2005;34:415-23

Gouni-Berthold I, Seul C, Ko Y, Hescheler J, Sachinidis A. Gangliosides GM1 and GM2 induce vascular smooth muscle cell proliferation via extracellular signal-regulated kinase 1/2 pathway. Hypertension 2001;38:1030-7

Graus F, Cordon-Cardo C, Houghton AN, Melamed MR, Old IJ. Distribution of the ganglioside GD3 in human nervous system detected by R24 mouse monoclonal antibody. Brain Res 1984;324:190-4

Hakomori S. Functional role of glycosphingolipids. Modulators for trans membrane signaling and mediators for cellular interaction. J Biol Chem 1990;265:18713-6

He Z, Li J, Zhen C, Feng L, Ding X. Knockdown of p53 RNAi in ES cells facilitates RA-induced differentiation into muscle cells. Biochem Biophys Res Commun 2005;335:676-83

Higashi $\mathrm{H}$, Chen NH. Ganglioside/protein kinase signals triggering cytoskeletal actin reorganization. Glycoconj J 2004; 20:49-58

Kawai H, Sango K, Mullin KA, Proia RL. Embryonic stem cells with a disrupted GD3 synthase gene undergo neuronal differentiation in the absence of b-series gangliosides. J Biol Chem 1998;273:19634-8

Kim JH, Do HJ, Yang HM, Oh HJ, Choi SJ, Kim DK, Cha KY, Chung HM. Overexpression of SOX9 in mouse embryonic stem cells directs the immediate chondrogenic commitment. 2005;37:261-8

Kotani M, Kawashima I, Ozawa H, Terashima T, Tai T. Differential distribution of major gangliosides in rat central nervous system detected by specific monoclonal antibodies. Glycobiology 1993;3:137-46

Kotobuki N, Hirose M, Takakura Y, Ohgushi H. Cultured autologous human cells for hard tissue regeneration: preparation and characterization of mesenchymal stem cells from bone marrow. Artif Organs 2004;28:33-9

Kwak DH, Rho YI, Kwon OD, Ahan SH, Song JH, Choo YK, Kim SJ, Choi BK, Jung KY. Decreases of ganglioside GM3 in streptozotocin-induced diabetic glomeruli of rats. Life Sci 2003;72:1997-2006

Leahy A, Xiong JW, Kuhnert F, Stuhlmann H. Use of developmental marker genes to define temporal and spatial patterns of differentiation during embryoid body formation. J Exp Zool 1999;284:67-81

Ledeen RW, Yu RK. Gangliosides: structure, isolation, and analysis. Methods Enzymol 1982;83:139-91

Li R, Manela J, Kong Y, Ladisch S. Cellular gangliosides promote growth factor-induced proliferation of fibroblasts. J Biol Chem 2000;275:34213-23

Liour SS, Yu RK. Differential effects of three inhibitors of glycosphingolipid biosynthesis on neuronal differentiation of embryonal carcinoma stem cell. Neuronchem Res 2002;27:1507-12

Martin GR. Isolation of a pluripotent cell line from early mouse embryos cultured in medium conditioned by teratocarcinoma stem cell. Proc Natl Acad Sci USA 1981;78:7634-8

Milne HM, Burns CJ, Kitsou-Mylona I, Luther MJ, Minger SL, Persaud SJ, Jones PM. Generation of insulin-expressing cells from mouse embryonic stem cells. Biochem Biophys Res Commun 2005;328:399-403

Nojiri H, Takaku F, Terui Y, Miura Y, Saito M. Ganglioside GM3; an acidic membrane component that increase during macrophage-like cell differentiation can induce monocytic differentiation of human myeloid and monocytoid leulcemic cell lines H2-60 and U937. Proc Natl Acad Sci USA 1986;83:782-6

Ogawa-Goto K, Funamoto N, Ohta Y, Abe T, Nagashima K. Myelin ganglioside of human peripheral nervous system: an enrichment of GM1 in the motor nerve myelin isolated from cauda equnia. J Neurochem 1992;59:1844-9

Okada Y, Shimazaki T, Sobue G, Okano H. Retinoic-acid-concentration-dependent a acquisition of neural cell identity during in vitro differentiation of mouse embryonic stem cells. Dev Biol 2004;275:124-42

Piao H, Youn TJ, Kwon JS, Kim YH, Bae JW, Sohn B, Kim DW, Cho MC, Lee MM, Park YB. Effects of bone marrow derived mesenchymal stem cells transplantation in acutely infracting myocardium. Eur J Heart Fail 2005;7:730-8

Stojiljkovic M, Blagojevic T, Vukosavic S, Zvezdina ND, Pekovic S. Ganglioside GM1 and GM3 in early human brain development: an immunocytochemical study. Int J Dev Neurosci 1996; $14: 35-44$

Svennerholm L. Quantitative estimation of sialic acid. II. A colorimetric resorcinol-hydrochloric acid method. Biochim Biophys Acta 1957;24:604-11

Svennerholm L. Gangliosides and synaptic transmission. In advances in experimental biology and medicine: structure and function of gangliosides. Adv Exp Med Biol 1980;12:533-44

Wei H, Juhasz O, Li J, Tarasova YS, Boheler KR. Embryonic stem cells and cardiomyocyte differentiation: phenotypic and molecular analyses. J Cell Mol Med 2005;9:804-17

Woodbury D, Schwaz EJ, Prockop DJ, Black IB. Adult rat and 
human bone marrow stromal cells differentiate in neurons. J Neurosci Res 2000;6:364-70

Zappone MV, Galli R, Catena R, Meani N, Biasi SD, Mattei E, Tiveron C, Vescovi AL, Lovell-Badge R, Ottolenghi S, Nicoli SK. Sox2 regulatory sequences direct expression of a beta-geo transgene to telencephalic neural stem cells and precursors of the mouse embryo, revealing regionalization of gene expression in CNS stem cells. Development 2000; 127:2367-82
Zhang E, Li X, Zhang S, Chen L, Zhang X. Cell cycle synchronization of embryonic stem cells: effect of serum deprivation on the differentiation of embryonic bodies in vitro. Biochem Biophys Res Commun 2005;333:1171-7

Zhao LR, Duan WM, Reyes M, Keene CD, Verfaillie CM, Low WC. Human bone marrow stem cells exhibit neural phenotypes and ameliorate neurological deficits after grafting into the ischemic brain of rats. Exp Neurol 2002;174:11-20 